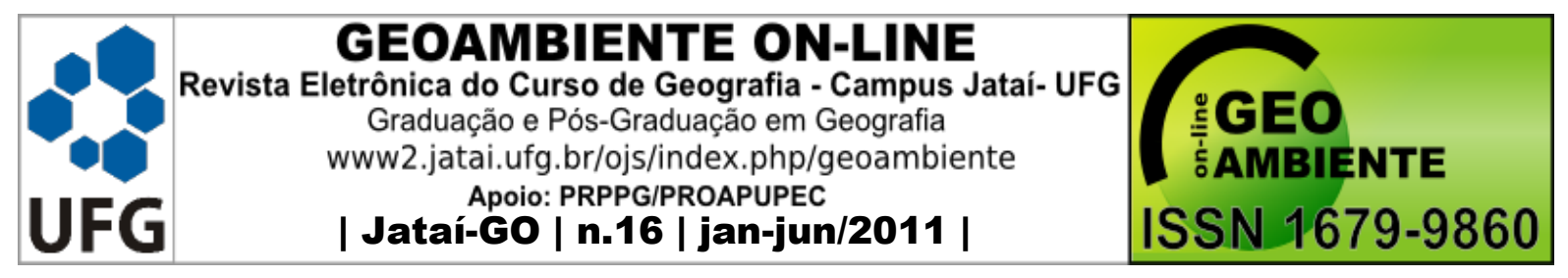

\title{
A CIÊNCIA HUMBOLDTIANA: SENSIBILIDADE E MENSURAÇÃO NA GÊNESE DA GEOGRAFIA FÍSICA
}

\author{
Antonio Carlos Vitte $^{1}$, Kalina S. Springer ${ }^{2}$ \\ (1 - Universidade de Campinas. Instituto de Geociências, Programa de Pós-Graduação em \\ Geografia, Campinas (SP), Brasil. CP 6152, CEP 13087-970, email: vitte@uol.com.br, 2 - \\ Universidade de Campinas. Instituto de Geociências, Programa de Pós-Graduação em \\ Geografia, Doutoranda em Geografia, Campinas (SP), Brasil. CP 6152, CEP 1308-970, email: \\ springer_kalina@yahoo.com.br)
}

\section{Resumo.}

O presente artigo tem por objetivo discutir o surgimento da geografia física a partir das reflexões e postulados da ciência humboldtiana. Essa formada (concordância) no contexto da naturphilosophie e no desenvolvimento de novos instrumentos e avanços das ciências exatas, permitindo a construção de um modelo de natureza e superfície da terra baseado no princípio transcendental das leis universais da natureza, materializadas em princípios regionais qual o método utilizado e a conclusão.

Palavras-Chave: Ciência Humboldtiana; Geografia Física; Naturphilosophie; Sensibilidade; Mensuração.

\section{Abstract. \\ HUMBOLDTIAN SCIENCE: MEASUREMENT SENSITIVITY AND THE GENESIS OF PHYSICAL GEOGRAPHY}

The study argues that the physical geography emerged from the ideas and postulates of science humboldtiana. That formed in the naturphilosophie and the development of new tools and advances in exact sciences, enabling the construction of a model of nature and the earth's

Artigo recebido para publicação em 28 de setembro de 2009

Artigo aprovado para publicação em 15 de Fevereiro de 2011 


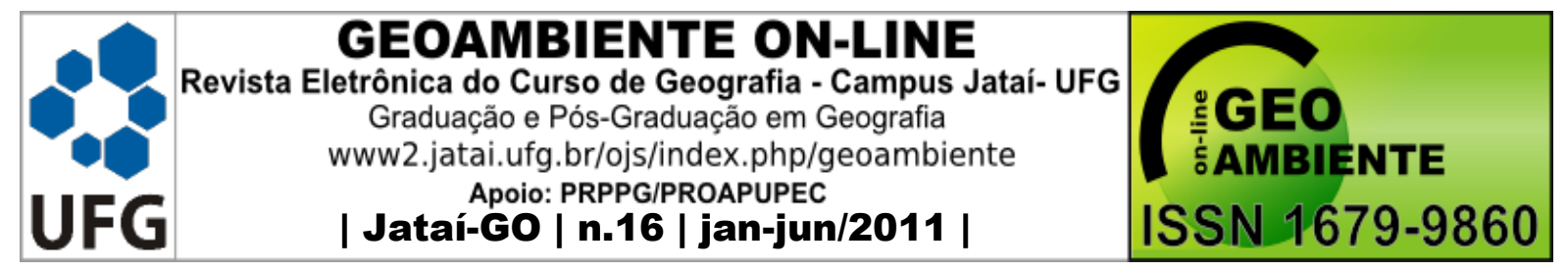

surface based on the principle of transcendental universal laws of nature, material on regional principles.

Keywords: Humboldtian Science, Physical Geography; Naturphilosophie; Sensitivity; Measurement.

\section{Resumen.}

\section{CIENCIA HUMBOLDTIANA: MEDICIÓN Y SENSIBILIDAD EN LA GÉNESIS DE LA GEOGRAFÍA FÍSICA}

Este artículo tiene como objetivo discutir el surgimiento de la geografía física conforme reflexiones y puntos de vista de la ciencia de Humboldt. Esta formado (acuerdo) en el contexto de la Naturphilosophie y el desarrollo de nuevas herramientas y avances en las ciencias, lo que permite la construcción de un modelo de la naturaleza y superficie de la tierra basada en el principio trascendental de las leyes universales de la naturaleza, y los principios consagrados en el método regional utilizados y la conclusión. Palabras clave: Ciencia de Humboldt; Geografía Física; Naturphilosophie; Sensibilidad; medición.

\section{Introdução}

O objetivo desse trabalho é demonstrar que a geografia física moderna possui sua gênese na ciência humboldtiana, que, por sua vez se desenvolveu as partir de uma relação dialética entre a naturphilosophie romântica ${ }^{1}$ (LENOIR, 1981), com o mecanicismo newtoniano.

Na matriz da naturphilosophie romântica, podemos localizar as reflexões de Schiller, Schelling, Goethe e Alexander von Humboldt. No entanto, para Georges Gusdorf (1985) é um tanto complexo e perigoso situar Alexander von Humboldt apenas na naturphilosophie romântica, pois para o autor (GUSDORF, op.cit) Humboldt está na encruzilhada epistêmica

Para Lenoir (1981), a naturphilosophie pode ser classificada em três fases, uma transcendental kantiana, uma romântica dominada pela filosofia-da-natureza de Schelling e pela concepção orgânica de kosmos e uma terceira corrente, a naturphilosophie metafísica, dominada pela filosofia da natureza de Hegel. 


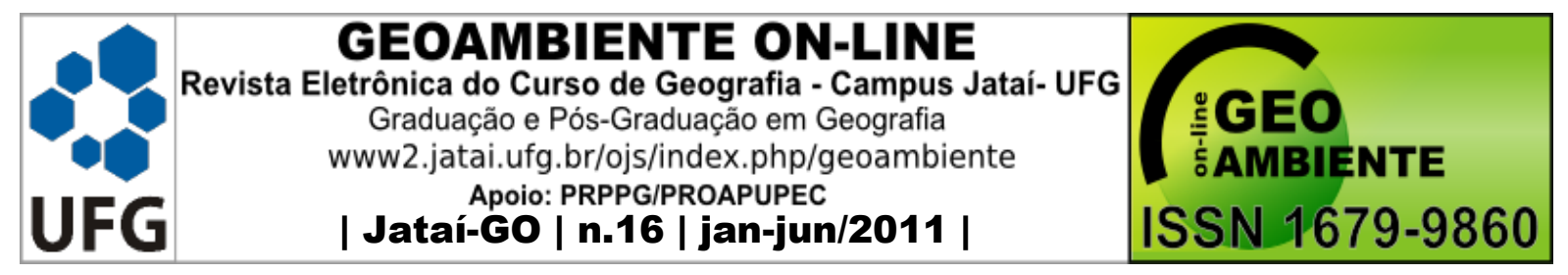

entre Schelling, Schopenhauer e Hegel, pois ao mesmo tempo em que manifesta fortes traços do idealismo romântico, marcado pelo vitalismo; permite a entrada do materialismo schopenhauriano transformado pela metafísica de "O mundo como vontade e representação" (SCHOPENHAUER, 2005) e pela complexa noção de matéria e ciência que caracterizou a discórdia entre Schpenhauer e Hegel (VITTE, 2007).

A nosso ver, a gênese da geografia física moderna situa-se justamente nesse contexto filosófico e epistemológico, cuja maior preocupação era justamente qualificar a superfície da Terra, a partir de uma enorme quantidade de dados coletados pelos viajantes. É nesse sentido, que mais do que descrição ou a sistematização de um inventário e sua correspondente hierarquização e distribuição em um espaço geométrico, que caracterizava a superfície da Terra até o século XVIII e sua transição para o XIX (CAPEL, 1995); antes, a geografia física representou a possibilidade de reflexão sobre a natureza e a conseqüente construção simbólica sobre a superfície da Terra e distribuição espacial da natureza na mesma e suas relações com a cultura.

Essa posição da geografia física frente à construção da modernidade foi garantida por um profundo debate filosófico, cujo amalgama foram à noção de espaço e a crítica radical a ciência mecanicista do século XVII.

Os motores que promoveram a desconstrução da concepção cartesiana-newtoniana de matéria e mecânica da matéria, fundamentos metafísicos para se pensar o espaço e a natureza; foi a revolução francesa e, de outro lado, a revolução kantiana, onde as noções de matéria, movimento como desenvolvidas nos Primeiros Princípios Metafísicos da Ciência da Natureza, de 1768 (KANT, 1990) e as noções de teleologia da natureza e de experiência estética, desenvolvida na Crítica do Juízo de Kant, em 1790 (KANT, 1995), foram fundamentais para des-teologizar a natureza e inventar a superfície da Terra e por conseqüência a geografia física.

\section{Naturphilosophie e Ciência}

O século XVIII foi fortemente impregnado pelo sentimento de Naturphilosophie nas reflexões filosóficas e científicas. Em primeiro lugar, haveria nesse sentimento uma 


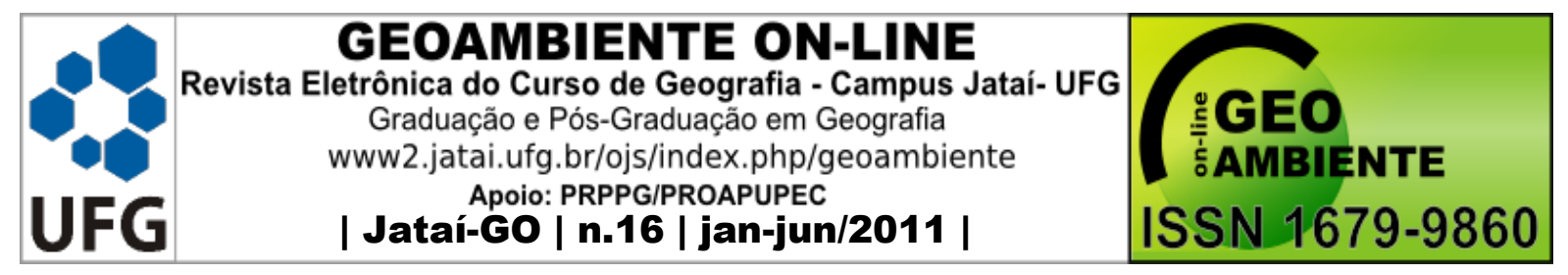

expectativa de explicação global da natureza. Por isso, pode-se entender desde a relação entre fenômenos físicos, químicos, biológicos, etc., como elementos necessariamente interconectados numa explicação do mundo - um kósmos, até uma compreensão dessa totalidade como, digamos, resultado de uma unidade que ressoaria em domínios interligados ciência, moral, estética. Em segundo lugar, há uma relação necessária com Kant e, conseqüentemente, com Newton.

A filosofia de Kant é também um acerto de contas com Newton: trata-se de, entre outras coisas, explicar a física newtoniana através da razão pura - o que não significa, por outro lado, que Kant apenas se mova em torno dessa intenção ou que ele simplesmente corrobore, na sua concepção de razão, as idéias de Newton. Por isso, é fundamental reconhecer a importância da obra de Kant nesse debate: desde a Crítica da razão pura até os Princípios metafísicos da ciência da natureza e a Crítica do Juízo. Em linhas gerais, uma questão que estes textos buscam resolver é a articulação entre mecanismo e finalidade.

Para Lenoir (1981) a questão da teleologia ou finalidade é o conceito central para a noção de organismo e, conseqüentemente, para a biologia nascente - pensada através de Kant e de sua Crítica do Juízo (1790).

A finalidade é o produto da causalidade, para os artefatos humanos, essa compreensão não suscita grande problema, mas para a natureza, como pensar a finalidade? Ainda mais se considerarmos que os fenômenos naturais estão no tempo e no espaço, submetidos a uma causalidade mecânica.

E, no entanto, a partir da experiência devemos construir leis universais (a priori) e leis particulares (empíricas), uma vez que os fenômenos naturais são desigualmente distribuídos na superfície da Terra.

A necessidade que se colocava então era a necessidade de se pensar em um sistema de conhecimentos empíricos possíveis: ou seja, um sistema de conhecimento (geografia física), em que a partir da premissa de uma unidade da natureza, articulasse o transcendental com o empírico, em um movimento, onde a finalidade da natureza fosse o eixo transversal da reflexão. 


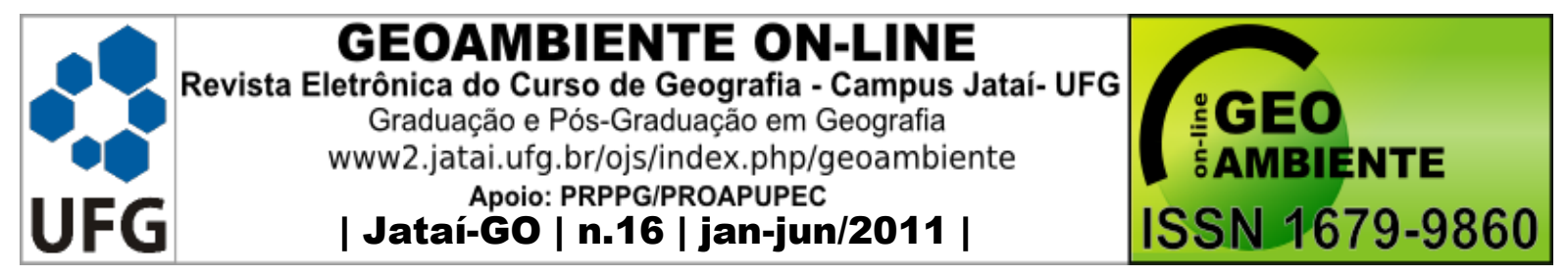

\section{A questão da sensibilidade}

O século XVIII pode ser considerado como a idade da sensibilidade (RISKIN, 2002), onde as críticas as concepções mecanicistas e materialistas que eram desenvolvidas pelos newtonianos perdurava na explicação da natureza e dos fenômenos naturais.

A discussão sobre a sensibilidade surgiu com o empirismo, doutrina que pregava que o conhecimento era originário da observação e do experimento, que afetaria a sensação do observador (RISKIN, 2002, p.1). Ainda segundo a autora (RISKIN, 2002, p.1), para Diderot a sensibilidade seria motivada pela capacidade de o observador em receber as impressões externas dos objetos. Essa capacidade seria dada pelo movimento do mesmo, que provocaria no observador um sentimento que descreveria a sensação física e emocional em relação ao objeto.

Para RISKIN (2002, p.1) esse seria o gérmen do pensamento do belo e do maravilhoso da natureza, que seria caracterizado por fenômenos singulares da natureza. Desse processo evoluiria o pensamento sobre as emoções do observador perante a beleza natural, sendo a base para o surgimento de paisagem no século XVIII.

De uma sensação física, a sensibilidade evolui para a noção de sensibilidade moral, permitindo já no século XVIII a busca de relações entre o belo natural e o desenvolvimento moral das nações.

A sensibilidade passou a guiar os trabalhos científicos no campo da psicologia, da medicina, da história natural e da geografia física; interferindo nas metodologias de pesquisa, nas epistemologias e nas estratégias de uso das técnicas e experimentos. É assim, que durante a naturphilosophie alemã, a união entre a sensibilidade e a ciência, gerou a concepção de uma visão estética da natureza, que guiou a construção de uma interpretação geográfica da superfície da Terra.

Há, assim, uma relação estreita entre as ciências naturais e o romantismo (CUNNINGHAM E JARDINE, 1990), marcada por uma forte introspecção, reflexão e pela sensibilidade, cimentada pela forte relação entre arte, natureza e ciência. 


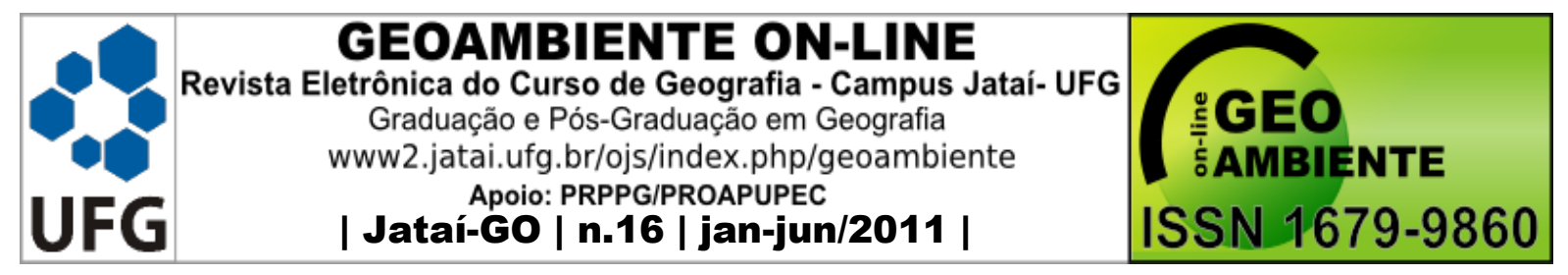

A geografia física, surgida no contexto da naturphilosophie, foi o produto da união entre o sentimentalismo e o empirismo, onde as suas teorias científicas foram o produto de uma relação complexa entre a sensibilidade e o newtonianismo, representada pela ciência humboldtiana.

\section{A Ciência Humboldtiana e a Geografia Física}

No século XVIII, as pesquisas nas ciências naturais foram fortemente impulsionadas pela faculdade estética e por uma forte crítica à concepção cartesiana-newtoniana de matéria, o que acarretou uma profunda reforma na filosofia natural, com o surgimento da geografia física.

As pesquisas sobre a natureza e sua qualificação resultaram no século XVIII de uma profunda correlação entre a sensibilidade, a imaginação e a estética, que irão redefinir os experimentos e a mensuração, uma vez que, a partir das influências da filosofia-da-natureza de Schelling (LENOIR, 1981), a natureza foi tomada com uma visão orgânica e de vitalismo.

Nesse contexto, o esforço da ciência humboldtiana, situada na tensão entre a naturphilosophie romântica e a metafísica; foi o de estabelecer uma visão integral da natureza e ao mesmo tempo leis particulares baseadas na mensuração precisa e no uso da sensibilidade.

A partir de um considerável acumulo de números e mensurações, a consciência de uma enorme variedade de fenômenos, e, acima de tudo, a consciência metafísica da unidade da natureza e da necessidade de se estabelecer leis transcendentais, ou seja, gerais, Humboldt, fundamentado ontologicamente nas noções de estética da Terceira Crítica (KANT, 1995) e experiência estética de F. Schiller.

Schiller (in: RICHARDS, 2002) desenvolveu o método da observação da paisagem como postura científica de se registrar a organicidade da natureza procurando estabelecer as suas relações causais, mas sem perder de vista o sentido estético e simbólico da natureza. Influenciado pelo vitalismo de Blumembach e de Schelling e pela estética de Schiller (RICHARDS, 2002), assim como pelos avanços da ciência newtoniana, principalmente com 


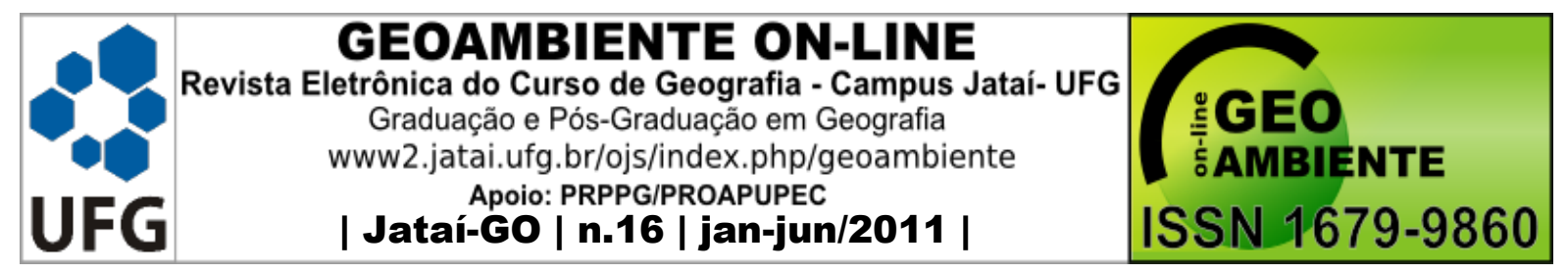

os instrumentos de medidas, Humboldt procederá a uma explicação física da natureza, a partir de uma precisão nas mensurações, com o desenvolvimento de inovações gráficas, cartográficas e no estabelecimento de relações causais entre os elementos da natureza e os processos da mesma, em um contexto regional, donde o espaço ou antes, a espacialidade da natureza será o produto do intercruzamento entre o materialismo newtoniano e a naturphilosophie.

Essa posição epistemológica conduz ao que Latour (2000) chamou de vida em laboratório, ou seja, a ciência humboldtiana inovou e produziu a modernidade na interpretação da natureza, pois conseguiu congelá-la, ou seja, transformar o que é móvel, dinâmico, em imóvel, para com isso manipulá-la, ou seja, torná-la de fato, objeto de pesquisa e intervenção. Tal inovação epistêmica e prática foi alcançada por meio do conceito de paisagem e de sua representação por meio da pintura que Humboldt tanto incentivava em seus trabalhos e viagens (VITTE, 2007).

\section{Conseqüências epistemológicas e metodológicas da ciência humboldtiana para a geografia física}

\section{A mensuração}

A concepção de mensuração desenvolvida por Humboldt, que será fundamental para o surgimento da cartografia temática, bem como para vários gráficos, isolinhas e perfis, que, cada qual, demonstrando a noção de organicidade e totalidade da natureza, fundamentado em uma concepção transcendental de natureza, não pode ser desconectada de sua época e do contexto filosófico. Assim, não podemos deixar de considerar que os grandes tratados de Alexander von Humboldt, foram gestados durante a nova química de Lavoisier, da noção de magnetismo e fluido elétrico de Coulomb, descobertas que alteraram a cognição e a sensibilidade do século XVIII. Obviamente, que o caldo que impregnou essas descobertas foi a revolução francesa e sua estética do terror.

É nesse contexto de naturphilosophie e a construção de uma nova metafísica da natureza, que a physique du monde de Humboldt, procurou reavaliar criticamente o conceito global de interação das forças físicas da natureza. 


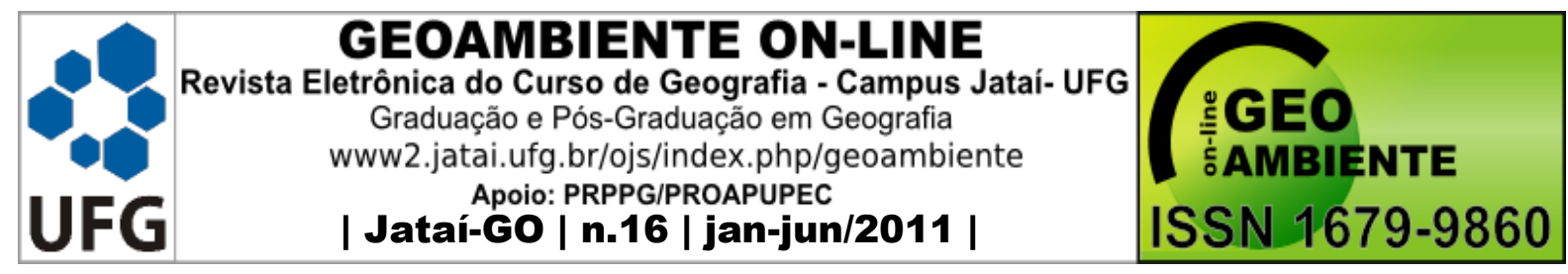

Para Humboldt, as ciências naturais não deveriam ficar presas apenas a conceitos antigos e concepções desenraizadas da empiria. A ciência deveria fazer uso de gráficos, linguagens simbólicas universais que de tal maneira que pudessem expressar resultados confiáveis.

Em suas pesquisas de geologia, Humboldt adotou a química e a termometria de Lavoisier, as técnicas de mensuração dos ângulos, desenvolvidas por Coulomb. Durante a preparação para a viagem para a América, comprou instrumentos modernos e de precisão em Viena e Paris (DETTELBACH, 1990).

Para Humboldt, o uso de instrumentos precisos, mensuração precisa, demandava o uso de uma linguagem precisa e uma sensibilidade especial para o registro da organicidadetotalidade da natureza. Para isso, o trabalho geográfico necessitava de um amplo realismo matemático com equações algébricas desenvolvidas, criações gráficas e cartográficas, de tal forma que se pudesse "transcendentalizar"a existência de substâncias puras em compostos, sempre utilizando a sensibilidade para a construção de arquétipos da natureza.

A partir do cânone regional, a diversidade da natureza é transcendentalizada e conjuntamente com a experiência estética, as leis universais poderiam ser construídas, o que explicaria a distribuição geográfica das paisagens naturais. Que será fundamental para o desenvolvimento da cartografia temática em Humboldt e da noção de perfil topogeográfico, como síntese da relação entre o particular e o universal; assim como essa matriz estética será importante para a construção da noção de unidade regional da natureza, cuja síntese pode ser representada pela pintura de paisagem.

O que perpassa a ciência humboldtiana e que a geografia física é a grande herdeira, é a crença ontológica no conceito de espaço, que se manifesta na noção de espacialidade, criada por Humboldt, onde a noção de paisagem será a síntese do transcendental, manifesta em princípios mecânicos e estéticos.

Para Humboldt, um instrumento de pesquisa tem a finalidade de, ao mensurar, influenciar a sensibilidade, e, a partir disso, a organizar a matéria da natureza, que para Humboldt é uma força vital. 


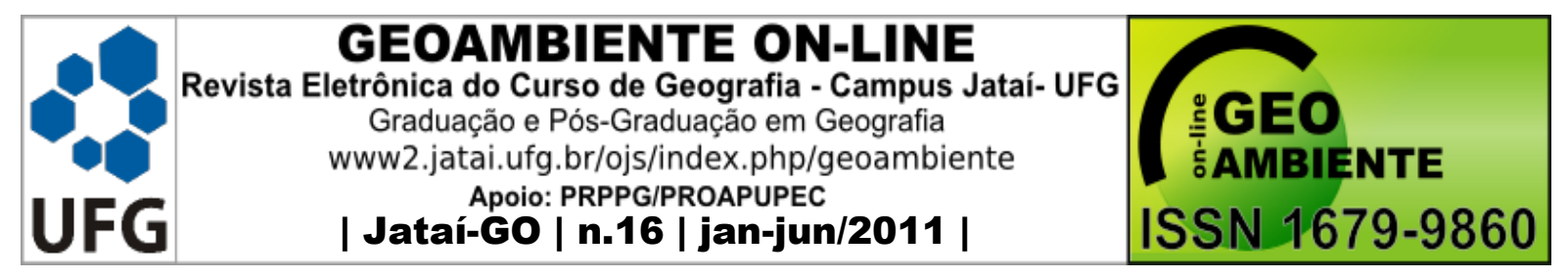

A crença no vitalismo, levou Humboldt a utilizar uma série de instrumentos, desde aqueles que detectavam pequenas mudanças químicas, até o barômetro. Para ele, isso era necessário para “... analyze the total impression made by nature on our organs” (LANGE E JAHN, 1973, p.584).

Assim, os gráficos expressavam as mensurações precisas e procuravam representar a realidade física, com que a natureza se manifestava ao observador, ou seja, marcado por uma forte sensibilidade, o observador poderia registrar as forças imateriais da natureza que plasmam a paisagem.

\section{Os Mapeamentos e as Construções Gráficas}

Os mapas, como o de isolinhas, talvez o mais famoso gráfico de Humboldt, expressava justamente o testemunho do poder e precisão da observação da natureza. Para Humboldt, um gráfico ou um mapa possuía o poder de comunicar a outros homens a beleza da natureza, tendo também um efeito educativo (RICOTTA, 2003).

A concepção humboldtiana fundamentava-se na premissa de que a natureza era dinâmica e as variáveis físicas eram irredutíveis, pois seriam o produto simultâneo de várias causas físicas. As isotermas, por exemplo, apesar dos artifícios matemáticos, das mensurações precisas, eram sempre irredutíveis, pois eram fenômenos físicos, não pré-determinados matematicamente,

Temperature and magnetism are not like those phenomena which, derived from a single cause or a central force, can ber freed of the influence of disturbing causes by restricting attention to the mean results of a great number of observations, in which these foreign effects reciprocally counteract and destroy one another. The distribution of heat, like the declination and inclination of the compass needle or the intensity of magnetic force, is essentially conditioned by location, composition of the soil, by the proper ability of the earth's surface to radiate heat. One must beware of eliminating what is sought; one must not classify as foreign and disturbing causes those upon which the most important phenomena in the distribution and the more rapid or slow development of organic life essentially depend. (HUMBOLDT, 1817, p. 462; In: FELDMANN, 1990, p.164-177).

Segundo Dettelbach (1990), o método das isolinhas, Humboldt desenvolveu a partir dos trabalhos do astrônomo e cosmógrafo, Tobias Meyer (1723-1762), professor em 


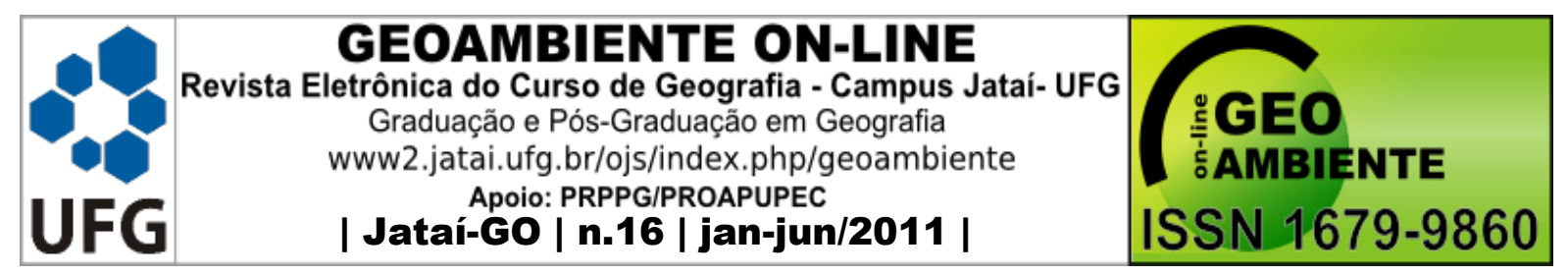

Göttingen e, que estava muito preocupado com a distribuição do calor na superfície da Terra. Dessa preocupação, Meyer desenvolveu a partir de equações de trigonometria, com coeficiente indeterminado, a curva de distribuição do calor solar sobre a superfície da Terra, a partir de uma relação entre o calor solar e o magnetismo da Terra.

O cálculo de Meyer era essencialmente matemático e geométrico, o que incorria em falta de precisão, o que levou Humboldt a se preocupar com as medidas geodésicas da Terra e a se preocupar com a construção de instrumentos mais precisos.

Para Dettelbach (1990), Humboldt aperfeiçoou o método das isolinhas de Meyer, na medida em que utilizou uma série de aparelhos para mensurar o calor solar e correlacionou-o com a distribuição da vegetação no globo, aperfeiçoada com o uso de uma tabela e de gráficos descritivos. Com isto, Humboldt instrumentalizou o princípio da Naturphilosophie sobre a correlação espacial. Essa correlação espacial foi alcançada metodologicamente na medida em que Humboldt considerou em um mesmo meridiano uma família de uma flora local e observou a sua variação em frações ao longo do paralelo do equador. Considerou que a vegetação não apresentaria variações bruscas, como a temperatura ou o magnetismo e em pontos fixos do gráfico, considerou também as possibilidades de variações entre a vegetação e seu ambiente (figura. 01). 


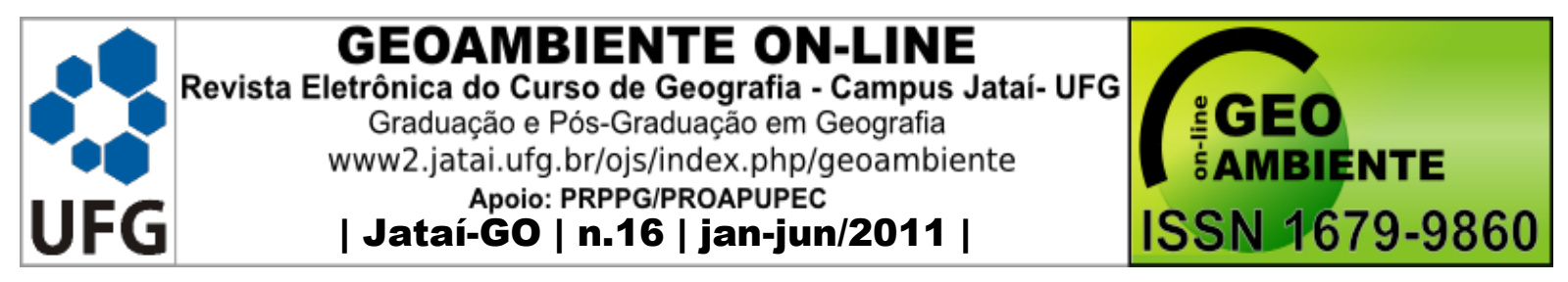

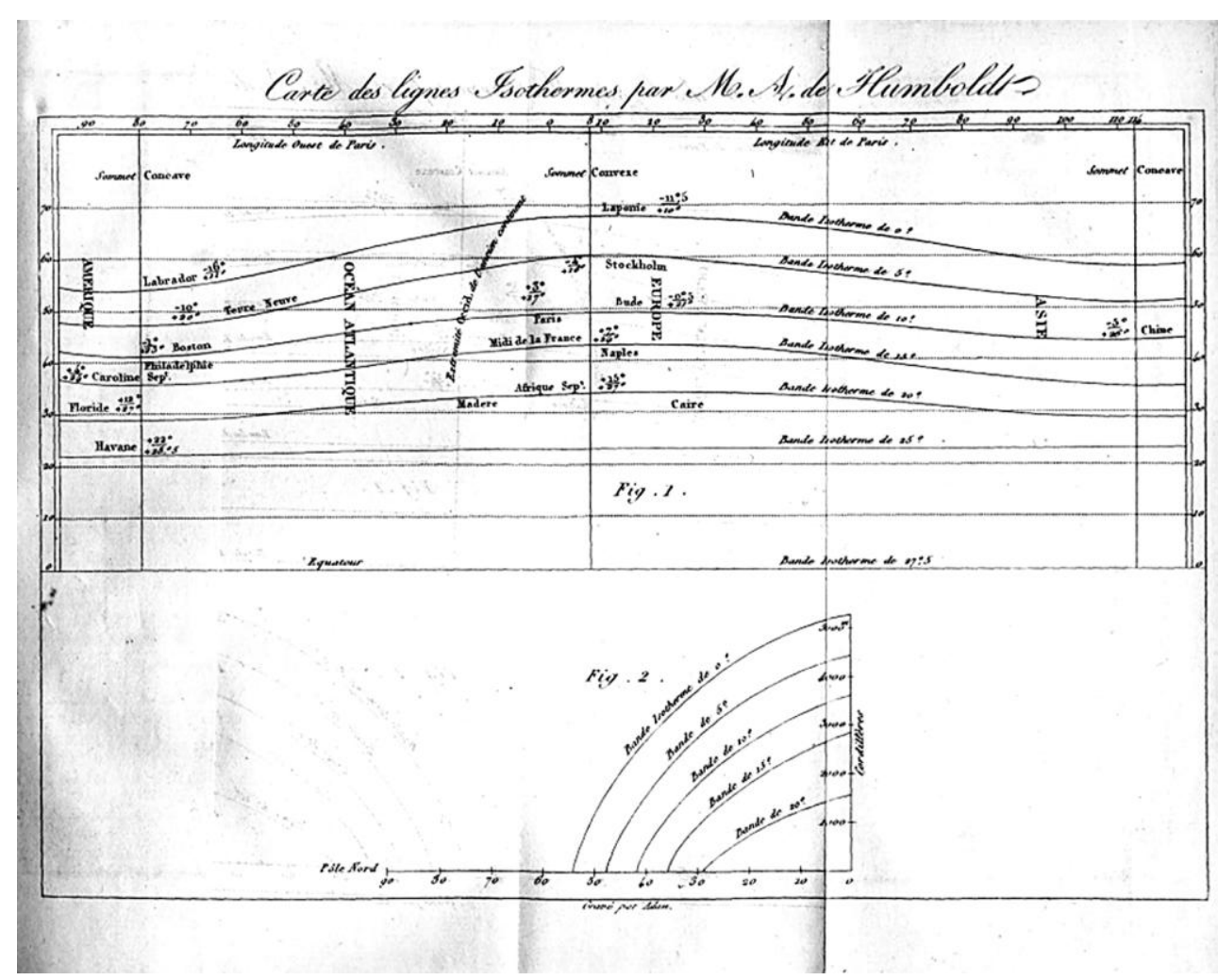

Figura 01. Planilha de mapeamento de isolinhas de Humboldt. (fonte: Nicolson, 1990:172).

Guiado pelo vitalismo e pelas reflexões sobre o influxo material de Blumembach, pela noção de orgânico de Kielmeyer, assim como pela noção kantiana de teleologia da natureza e de organismo, Humboldt desenvolveu a noção de que há um vitalismo na natureza, uma enteléquia que conduziu a relações e conexões nas mais diferentes escalas entre as entidades e que se manifesta na paisagem. A isso Humboldt chamará inicialmente de "fisiogonomia" da paisagem, que permite não apenas o conhecimento mecânico da natureza, da paisagem, que é a fisiologia, mas também a descoberta de uma arqueologia da natureza, de tempos acumulados, como dizia Leibniz.

Com isto, Humboldt, impõem assim, aos estudos da natureza a noção de variação escalar, mas sob o aspecto geográfico-temporal, ou seja, o princípio da transformação da natureza, a epigenia kantiana, materializada e instrumentalizada na noção de "físiogonomia" da paisagem, que evoluirá para os conceitos de fisiologia e de geoesfera, que serão as bases de construção da moderna geografia física e que tanto influenciou Charles Darwin e 


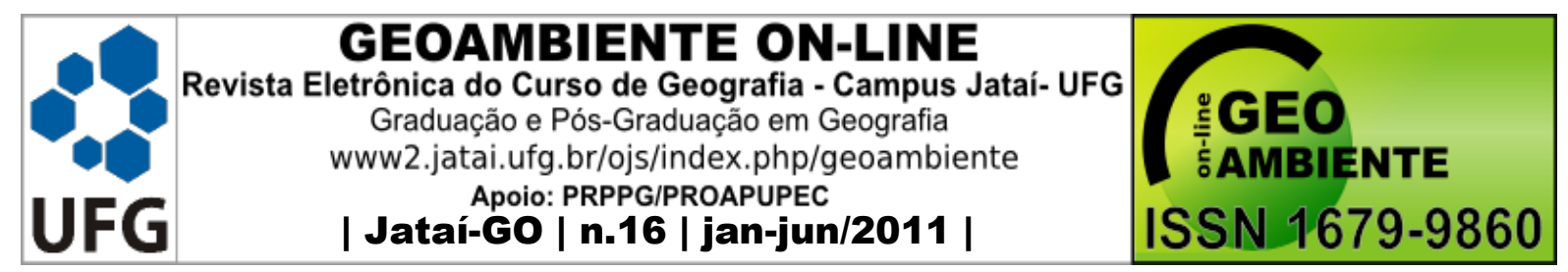

futuramente os estudos de Ratzel sobre as diferenças entre as paisagens históricas e as naturais, além de Passarge na geomorfologia (RATZEL, 1906; RICHARDS, 2002; VITTE, $2007 ; 2010)$.

A ciência humboldtiana apresenta várias faces, onde o projeto estético da naturphilosophie definiu uma concepção teleológica, holística e que a natureza e a cultura humana estão profundamente interligadas.

Ao mesmo tempo, Humboldt garantiu espaço para o surgimento da geografia física, que guiada por um senso estético, mas também por um profundo conhecimento causal de relações entre os fenômenos, ou seja, uma forte influência do materialismo newtoniano. Com isto, Humboldt demonstrou a complexidade em se analisar a natureza e a construção simbólica do conceito de paisagem, instrumentalizado na geografia física pelo conceito de geoesfera, que representaria o produto de múltiplas causas e interações, redefinindo assim a lei da causalidade nos estudos geográficos. Humboldt foi o responsável não apenas pela criação da geografia física, marcada pela metafísica da causalidade, mas, também, pela introdução da história da natureza nessa mesma geografia física, na medida em que considerou que vários climas se sucedem ao longo do tempo e deixam suas marcas nos estratos, o que permite, por meio da mensuração, da observação e da correlação espacial, reconstruir a história da natureza em paleoespaços e ao mesmo tempo representá-la em pinturas de paisagem.

\section{Conclusão}

- Para nós, a questão central é que Humboldt vivendo as tensões da Naturphilosophie como apresentadas por Lenoir (1981) e ao mesmo tempo utilizando-se dos métodos e técnicas materialistas advindos da ciência newtoniana aponta para um impasse, uma tensão epistemológica se estabelece em Humboldt, pois o que está em jogo é mais do que uma "sensibilidade calibrada", antes disso, é a criação de uma forma de agir e pensar cientificamente que são de todo original, ou seja, a solução para Humboldt, advém com a criação da Ciência Geográfica. Diríamos nós, a transmutação da Ciência Humboldtiana para a Geográfica, que assume conscientemente essa tensão, fruto da confluência de diferentes legados a um tempo empírica e ordenadora e, a outro, sensível e imaginativa, 


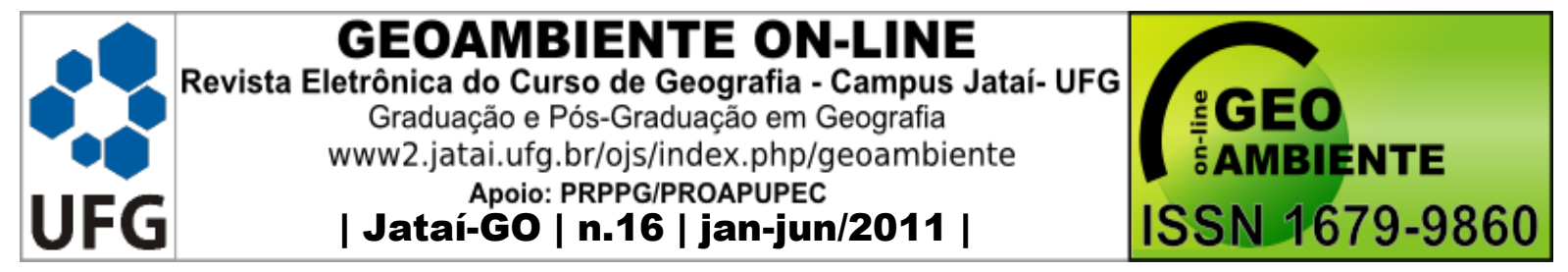

instrumentalizada pelo conceito de paisagem geográfica. Na sua grande obra, o Cosmos, que expressa verdadeiramente seu propósito e conflui suas idéias no que chamamos aqui de ciência humboldtiana, encontramos a manifestação do próprio Humboldt acerca do que está a produzir e da originalidade da ciência por ele criada.

- Essa ciência, a Geografia é mais do que se entende até então por ciência; ela é a confluência de múltiplos legados metodológicos; é a valorização do empírico e do transcendental, é a resposta, pelo conceito de paisagem, ao problema ontológico das aparentemente excludentes cosmovisões materialista e idealista. A Geografia, busca ordenações matemáticas para os fenômenos, a regularidade reconhecida na experiência pelo método de indução, assim como a compreensão de um telos natural, um conjunto de conexões reconhecidas na forma, o passo decisivo na introdução de uma sensibilidade romântica para além dos ditames restritos de uma ciência racionalista. Sintetizadora, essa ciência geográfica agrega não só diferentes legados, mas também, no reconhecimento espacial das variações, na apresentação regional de características próprias segundo princípios regulares, os elementos da natureza na sua relação harmônica com ela mesma e com o espírito, compreendidas nesse sentido sob o conceito de paisagem. Para além dos limites reconhecidos, a ciência humboldtiana, agora Geografia, é uma ciência universal que procura apaziguar todos os caminhos dispostos ao humano em sua história intelectual. Científica, artística e filosófica, sua ciência representa o esforço de quem pretendeu com sua vida intelectual resolver com uma construção científica original o problema ontológico que acompanha a história do conhecimento, na qual a Geografia é a grande herdeira.

\section{Bibliografia}

CAPEL, H. Ramas em el árbol de La ciência. Geografía, Fisica e Historia Natural en lãs expediciones náuticas del siglo XVIII. In: TORRE, A.R.D; MALO, T. e FERNANDEZ, D.P. (orgs) De la ciência ilustrada a la ciencia romántica. Madrid: Doce Calles, 1995, p.503-537.

CUNNINGHAM, A. e JARDINE, N. (edts) Romanticism and the sciences. Cambridge and New York, Cambridge University Press, 1990. 


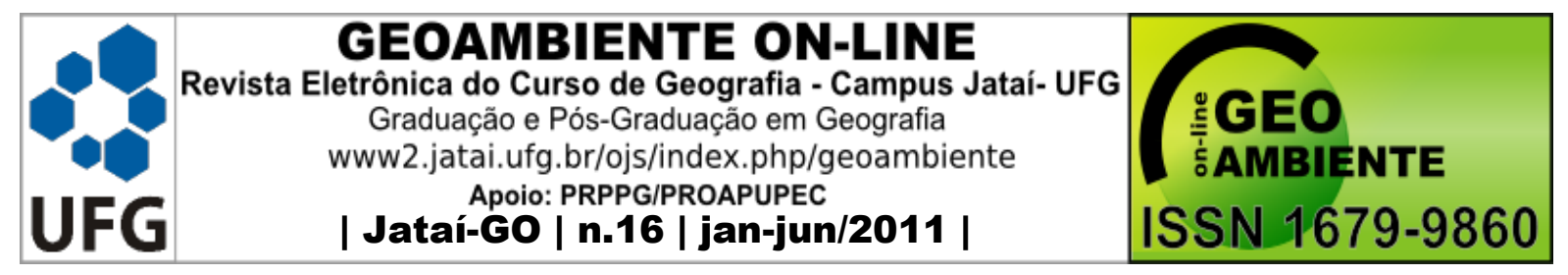

DETTELBACH, M. Romanticism and administration. In: CUNNINGHAM, A. e JARDINE, N. (edts) Romanticism and the sciences. Cambridge and New York, Cambridge University Press, 1990, p. 193-207.

FELDMAN, T. Late Enlightenment Meteorology. In: HEILBRON, T.; FRANGSMAYER, T. \& RIDER, R. (Edts) Quantifying Spirit. Berkeley: University of California Press, 1990, p.164-177.

Gusdorf, G., Le savoir romantique de la nature. Paris, Payot, 1985.

KANT, I. Princípios metafísicos da ciência da natureza. Porto: edições 70, 1990.

KANT, I. Crítica da Faculdade de Julgar. RJ: Forense Universitária, 1995.

LANGE, F. e JAHN, I. (edts) Die Jugendbriefe Alexander von Humboldts. Berlin: Akademie, 1973, p.584-657.

LATOUR, B. Ciência em Ação. SP: Editora da Unesp, 2000.

LENOIR, T. The Göttingen School and the Developement of Transcendental Naturphilosophie in the Romantic Era. COLEMAN, W. e LIMOGES, C. (orgs) Studies in History of Biology. Baltimore and London, John Hopkins University Press, 1981, p. 111 a 205.

NICOLSON, M. Alexander von Humboldt and the geography of vegetation. In: CUNNINGHAM, A. \& JARDINE, N. (ed.) Romanticism and the sciences. Cambridge: Cambridge University Press, 1990, p.169-189.

RATZEL, F. Über Naturfchilderung. München and Berlin, Drack und Berlag, 1906.

RICHARDS, R.J. The romantic conception of life. Chicago and London: Chicago University Press, 2002.

RICOTTA, Lúcia. Natureza, Ciência e Estética em Alexander von Humboldt. RJ: Mauad, 2003.

RISKIN, J. Science in the age of sensibility. Chicago and London: Chicago University Press, 2002.

SCHOPENHAUER, A. O mundo como vontade e representação. SP: editora da Unesp, 2005. 


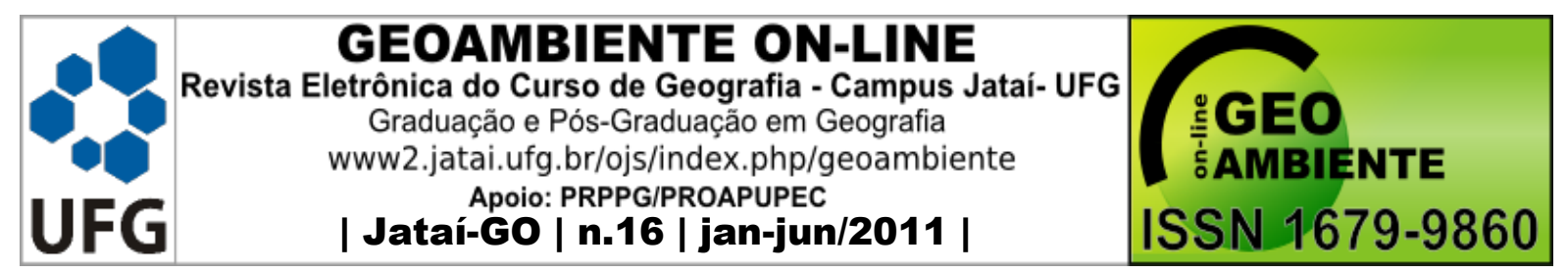

VITTE, A.C. Da metafísica da natureza à gênese da geografia física moderna. In: VITTE, A.C. (org.) Contribuições à história e à epistemologia da geografia. RJ: Bertrand Brasil, 2007a, p. 11-47.

VITTE, A.C. O desenvolvimento do conceito de paisagem e a sua inserção na geografia física. Revista Mercator,UFC, vol. 6, n. 11, 2007, p.59-70.

VITTE, A.C. As relações entre o Positivismo, o Darwinismo e a Teologia na Institucionalização da Geografia na Alemanha no século XIX. (projeto de pesquisa), 2010. 